\title{
A new paradigm in ground support monitoring through ultrasonic monitoring of clusters of rockbolts
}

\author{
Z Sun National Research Council of Canada, Energy, Mining and Environment Research Centre, Canada \\ KT Wu National Research Council of Canada, Energy, Mining and Environment Research Centre, Canada \\ SE Kruger National Research Council of Canada, Energy, Mining and Environment Research Centre, Canada \\ D Levesque National Research Council of Canada, Energy, Mining and Environment Research Centre, Canada \\ D Gagnon National Research Council of Canada, Energy, Mining and Environment Research Centre, Canada \\ Y Quenneville National Research Council of Canada, Energy, Mining and Environment Research Centre, Canada
}

R Lacroix Natural Resources Canada, Canada

R Royer Natural Resources Canada, Canada

\begin{abstract}
In most of today's underground mines, ground support monitoring is mainly conducted through using microseismic sensors, LiDAR, extensometers, cameras, or visual inspection. These monitoring tools are complementary in nature. Due to high costs associated with purchase, installation, maintenance and utilisation, they are usually deployed or used at sparsely selected critical locations, some of them on a non-continuous basis. This means that some important pieces of information on ground support conditions may be missing either location-wise or time-wise.

In the last four years, the Energy, Mining and Environment Research Centre of the National Research Council Canada (NRC), in collaboration with CanmetMINING of Natural Resources Canada (NRCan), has developed next generation ultrasound rockbolt sensors $\left(R B S^{T M}\right)$ for monitoring load change and deformation experienced by rockbolts. Intrinsically low costing and installation onto exposed end of rockbolts using production bolters, the technology is meant to be deployed on a large number of rockbolts whereby the instrumented rockbolts become a network of ground condition sensors to provide on-demand 3D mapping of ground stress change and deformation all over excavated zones. Field trial data collected in a production mine has demonstrated that monitoring a cluster of rockbolts can provide much more meaningful and reliable information about ground condition when compared with information provided by a single instrumented rockbolt. Therefore, monitoring clusters of rockbolts is recommended as being an effective practice for ground support monitoring.
\end{abstract}

Keywords: rockbolt sensor, RBS, rockbolt inspection, rockbolt monitoring, rebar bolt monitoring, bolt elongation monitoring, bolt load monitoring, ultrasound, ground support mapping

\section{Introduction}

Rockbolts are important components of ground support systems. It is estimated that hundreds of millions of rockbolts are installed annually in mines and tunnels worldwide. The types and quantities of rockbolts to be deployed in a mine depend on ground condition as well as bolt size and quality. It would be understandable that following certain seismic events, for instance, those caused by blasting, some areas in the mine may need to be reinforced with more bolts because the ground has moved in such a way that these areas are more prone to ground falls than they were, or the integrity of some bolts have been compromised by ground deformation. Therefore, there are needs to monitor both ground activities and integrity of rockbolts installed. In most of today's underground mines, ground condition monitoring is mainly conducted through microseismic sensors, LiDAR, extensometers, cameras, or visual inspection. Due to high costs associated with purchase, installation, 
maintenance and utilisation, they are usually deployed or used at sparsely selected critical locations, some of them on a non-continuous basis. This means that some important pieces of information on ground support conditions may be missing either location-wise or time-wise.

Integrity of rebar bolts is mostly assessed through visual inspection. Pull tests are arguably the second most used means. Different methods have been proposed to instrument rebar bolts for monitoring load distribution along instrumented bolts. An often-applied approach consists of embedding a number of strain gauges in grooves machined along the length of a rockbolt (Hyett 2013; Li et al. 2012; Vlachopoulos et al. 2018) and installing the instrumented bolt in a rock mass. Strain gauges can be based on measurement of strain-induced change in electrical resistance, inductance, capacitance, frequency of a vibrating wire, and frequency shift of an optical signal. The most serious drawback of embedded sensing approaches is a lack of robustness. Sensor assemblies could be damaged easily by rock deformation and even by the bolt installation process (Hyett 2013). Secondly, the presence of grooves on the bolt could reduce the bolt strength by $10 \%$ (Charette \& Hyett 2013). Thirdly, the number of strain gauges that can be embedded in one groove is rather limited (for example three) due to space limitation. Therefore, only a few points along the bolt can be monitored. Distributed fibre optic strain sensing can be embedded in a groove of a rockbolt to achieve higher spatial resolution than other types of strain gauges. However due to its relatively high cost, this fibre optic technology is not suitable for monitoring a large number of underground rockbolts. Fourthly most strain gauges cannot measure strains larger than $5 \%$ and will fail once the instrumented bolt elongates by more than $5 \%$.

Application of ultrasound to rockbolt condition monitoring has been explored by researchers around the world. An attractive feature of ultrasound technologies is the possibility of mounting an ultrasound sensor at the exposed end of a rockbolt for bolt condition monitoring in a non-destructive manner. There have been efforts aiming to inspect rockbolt grouting conditions using relatively low frequency ultrasonic waves, mostly in the order of several tens of $\mathrm{kHz}$. Diagnostic acoustic waves are either generated with an ultrasound transducer or with help of an impact hammer (Fishman 2004, 2005; Zou et al. 2010; Yu et al. 2013). Applications of MHz frequency ultrasound to inspection of rockbolt integrity have been investigated, mainly on theoretical aspects of guided ultrasonic waves in rockbolts (Beard et al. 2002, 2003; Wu et al. 2007).

In the last four years, the Energy, Mining and Environment Research Centre of the National Research Council Canada (NRC), in collaboration with CanmetMINING of Natural Resources Canada (NRCan), has developed a next generation ultrasound rockbolt sensors $\left(\mathrm{RBS}^{\mathrm{TM}}\right)$ for monitoring load change and deformation experienced by rockbolts in a full dynamic range up to rupture. Recent field trials in a production mine have shown that the RBS technology was capable of producing valuable information about conditions of rockbolts and that changes in rockbolts conditions correlated closely with changes in ground conditions. Therefore, the RBS technology would serve the purposes of rockbolt condition monitoring and ground condition monitoring at the same time. This paper will present some field deployment results of the RBS technology.

\section{Instrumented rockbolts and field deployment}

Rebar bolts manufactured by DSI Underground Canada were instrumented. The instrumented bolts were $1.88 \mathrm{~m}$ long and $22 \mathrm{~mm}$ in diameter (rebar \#7, grade 60). Each of them had a blunt toe and was divided into three sections by two holes, with the first one being $1 \mathrm{~mm}$ in diameter and half depth to the centre line of the bolt, and the second one being a through hole of $1.5 \mathrm{~mm}$ diameter passing the centre line of the bolt (Figure 1).Instrumented bolts were installed using a MacLean bolter and grouted with resins provided by the mine site. An ultrasound rockbolt sensor was installed at the exposed end of the instrumented bolt and was either wired to a multichannel RBS system (MHub) for continuous monitoring (Figure 2), or equipped with a conic adaptor for manual inspection using a portable RBS system (Figure 3). In the latter case, the RBS sensor was also equipped with an RFID tag for bolt identification and a passive antenna for excitation and detection of ultrasound signals via a detection cup. The RBS sensor transmitted ultrasonic waves into the bolt and captured echo signals reflected off the 1 st and 2 nd holes as well as the bolt end (Figure 1). The duration needed for ultrasonic waves to travel the length of each of the three sections as well as the entire bolt length were measured and used to determine the average load change or deformation experienced by the bolt or a bolt section of interest since sensor installation. 


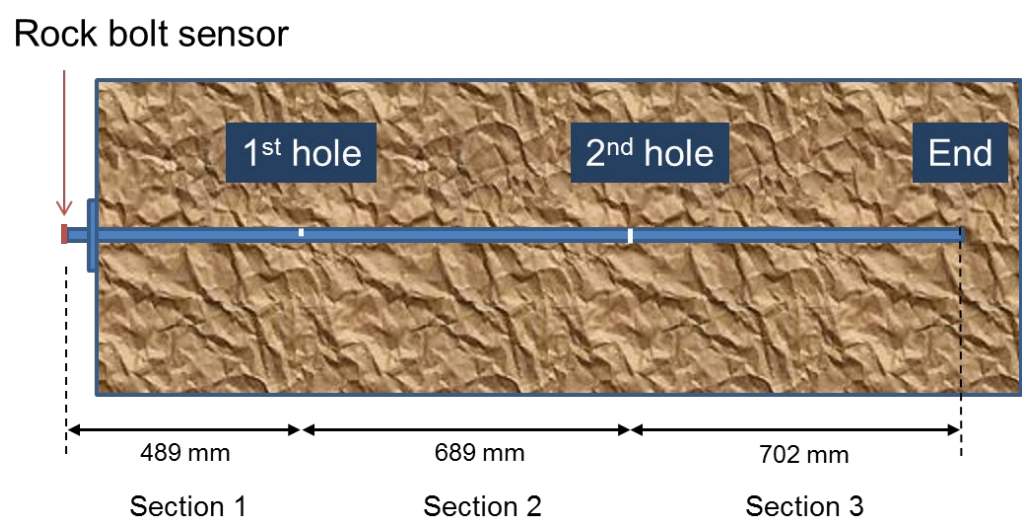

Figure 1 Instrumented rockbolt is divided into three sections with two holes

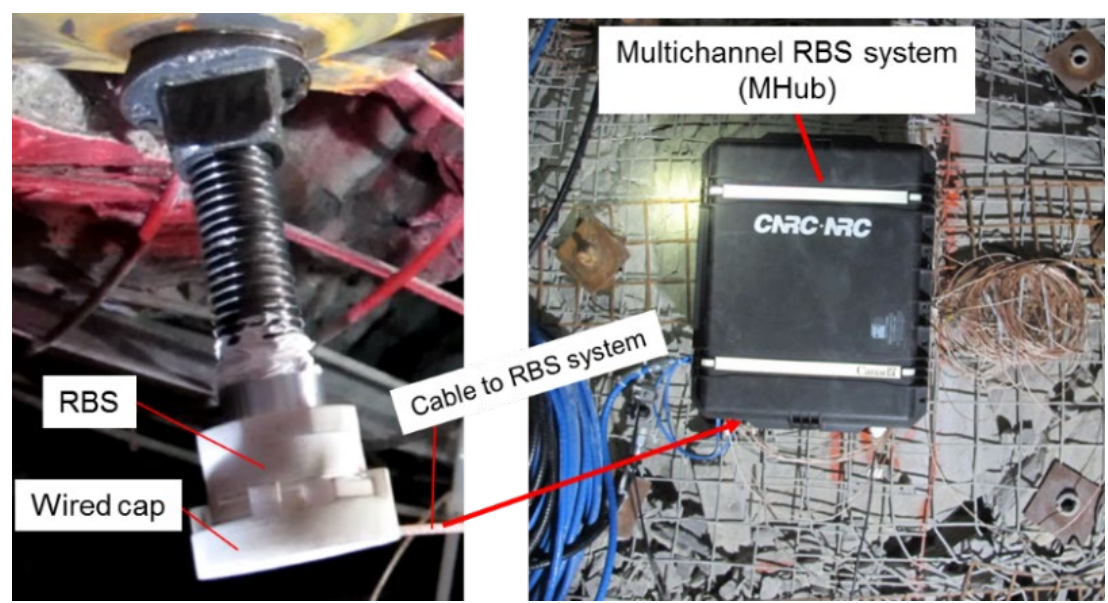

Figure 2 Rockbolt sensor (RBS) installed on the exposed end of a rockbolt and wired to a multichannel RBS system (MHub) for automatic continuous monitoring

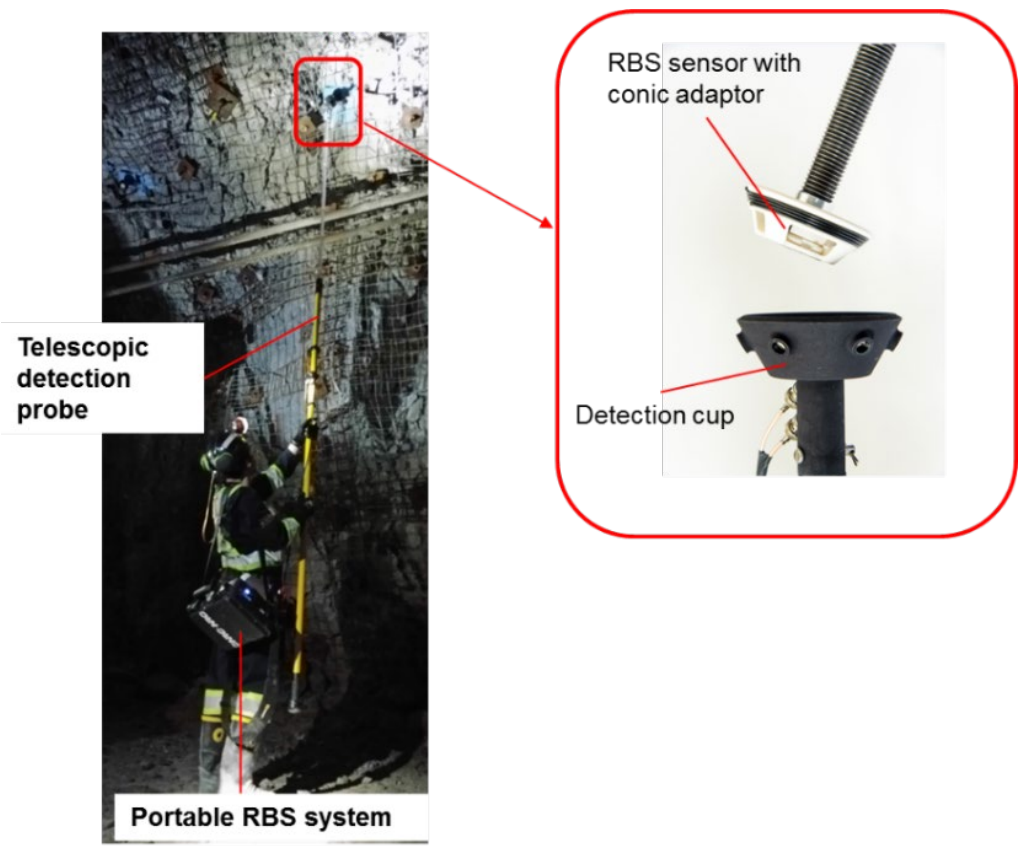

(a)

(b)

Figure 3 Rockbolt sensor (RBS) installed on the exposed end of a rockbolt and equipped with a conic adaptor (b) for manual inspection using a portable RBS system and a telescopic detection probe (a) 
Two sites were selected for RBS deployment. The first site, noted as site A, was under development and was selected for continuous automatic monitoring using a multichannel RBS system. This site was expected to experience moderate ground activities during the RBS deployment period. The plan of the site and layout of instrumented bolts are shown in Figure 4. Since this was the first deployment, and due to lack of experience, some bolt installations failed. Successfully installed bolts are indicated with green boxes. The second site, noted as site B, was in the vicinity of production blasting (about $30 \mathrm{~m}$ from production head when instrumented bolts were installed) and was expected to experience large ground movements during the RBS deployment period. A portable RBS system was used for manual inspection of instrumented rockbolts in this area. The plan of the site and layout of instrumented bolts are shown in Figure 5. For this deployment, eight of nine instrumented bolts were successfully installed. Successfully installed bolts are indicated with green boxes.

\section{Site A (Multichannel RBS system)}
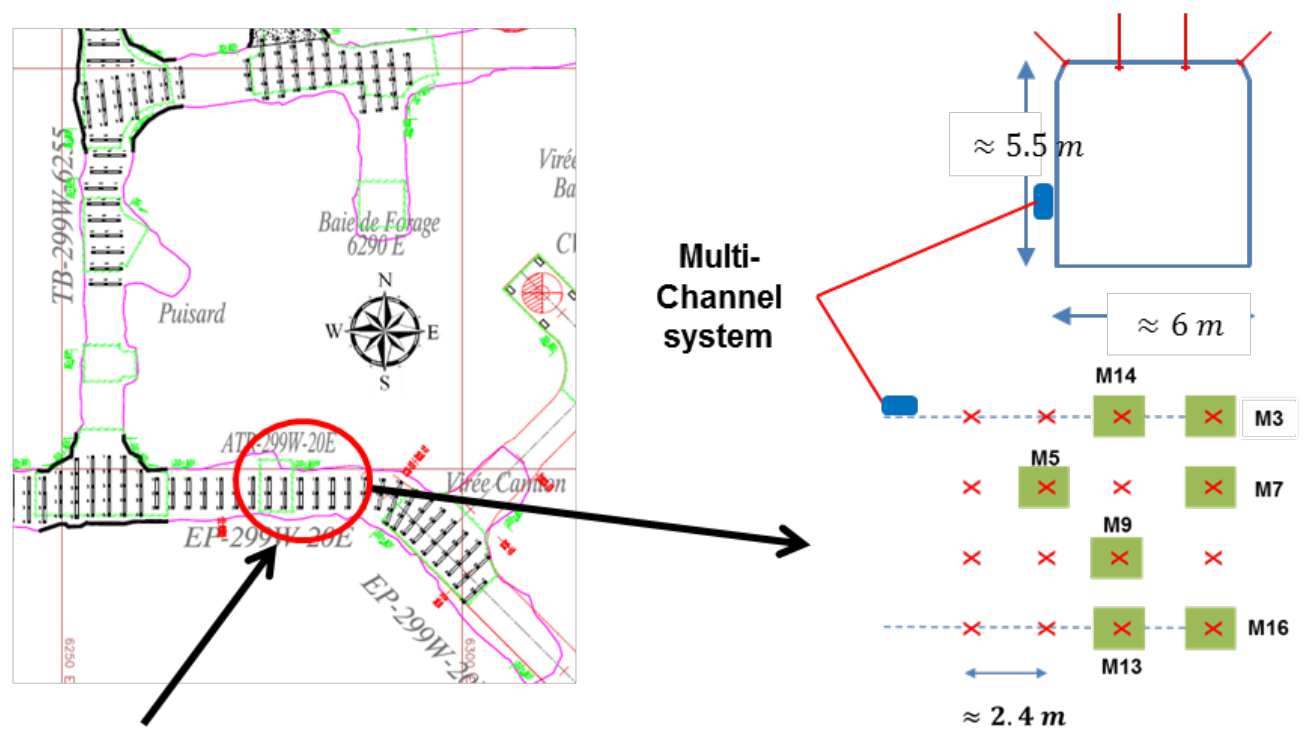

Instrumented area

Figure 4 Plan of site A and layout of instrumented rockbolts. Green boxes show bolts successfully instrumented. The dashed lines represent the corners where walls and back of the tunnel meet

\section{Site B (Portable RBS system)}

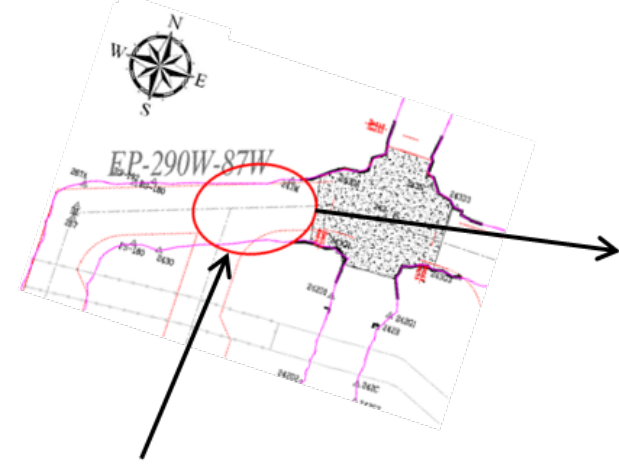

Instrumented area
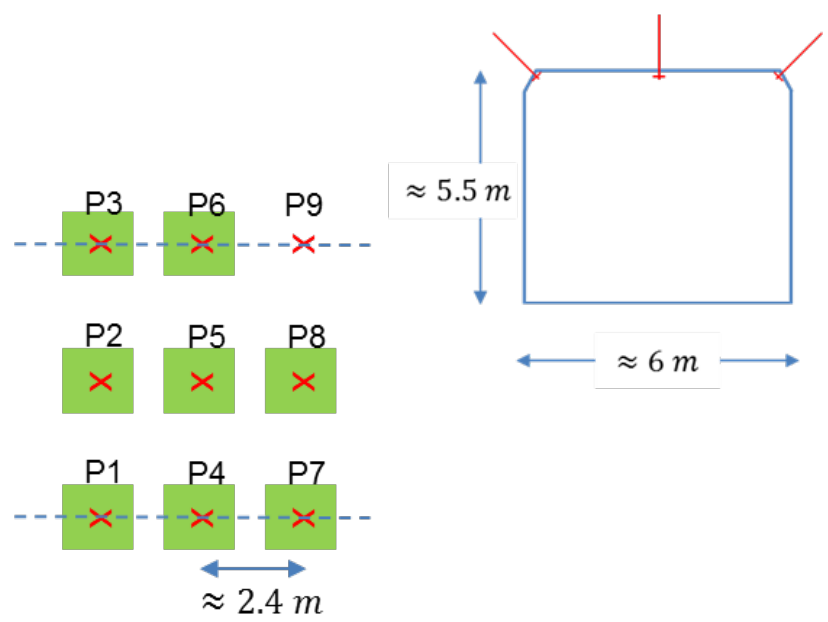

Figure 5 Plan of site B and layout of instrumented rockbolts. Green boxes show bolts successfully instrumented. The dashed lines represent the corners where walls and back of the tunnel meet 


\section{Results and discussion}

Figure 6 displays average load change over full length of instrumented rebar bolts at site $A$. The results are obtained by using ultrasonic echo signals from the end of rockbolts. Measurements between March 26 and April 4, 2018 were missing due to a malfunction of the multichannel system. On April 15, 2018 there was a production blast of 15,200 t at 5:15 PM. From 20:00 to 21:00, a sudden ground condition change was sensed by instrumented bolts M7, M9, M13 and M16. On May 13, 2018 there was a production blast of 13,000 t at 5:15 AM. Compared with April 15, 2018, a much more pronounced sudden load change was observed in the May 13 RBS measurements at 12:00 PM on all bolts except M3 and M14. However, RBS signals recorded at 6:00 AM on May 13 didn't yet show ground movement. The above observations suggest that, following a large production blast, there was a time delay for load change to transfer throughout the rock mass from the blast zone to the test site. It is also interesting to notice an increasing load change from the north side of the tunnel to the south side, with bolts M16 and M13 being located along the south wall displaying the most significant load increase.

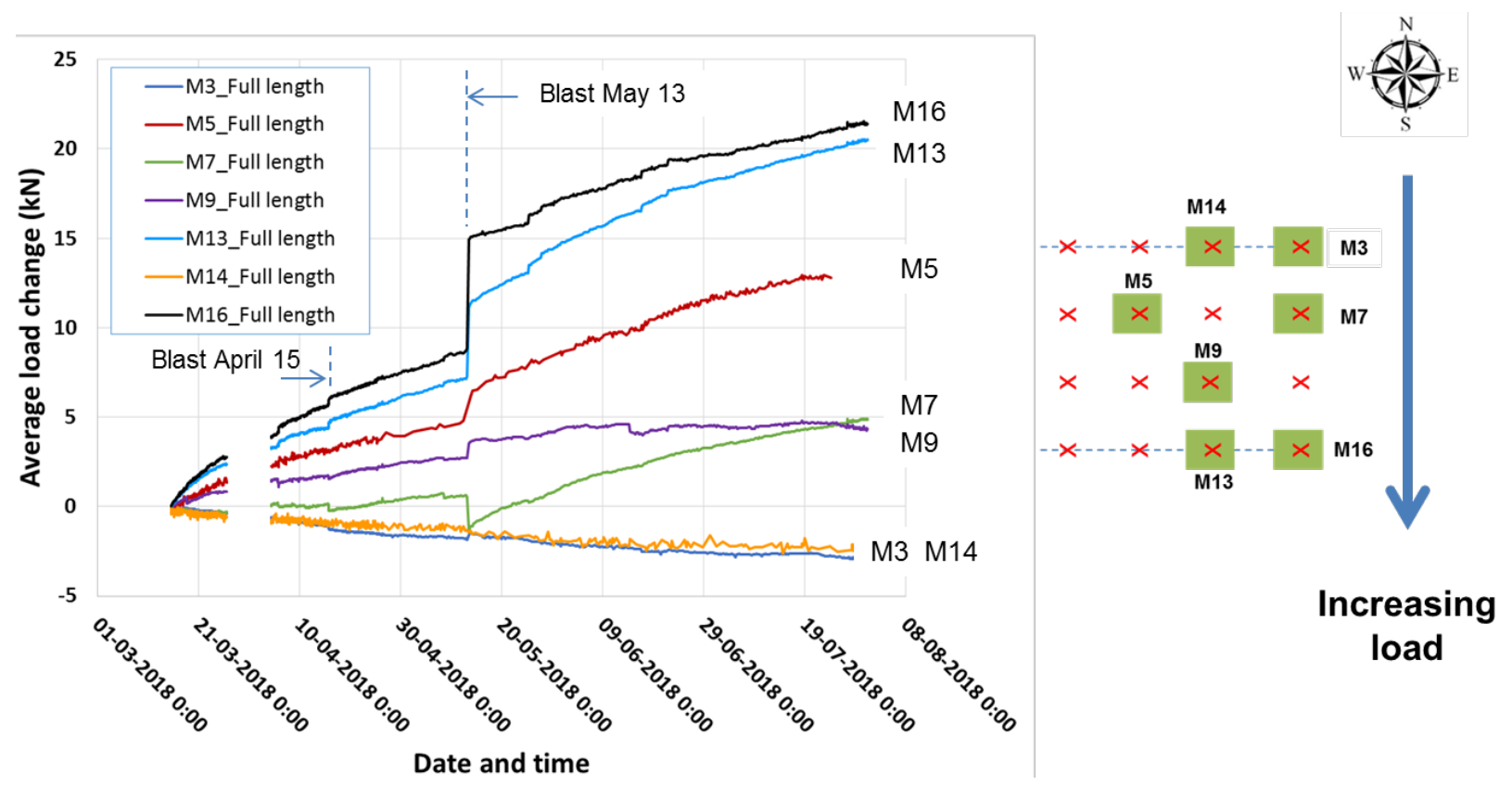

Figure 6 Average load change over full length of rockbolt at site A

Figure 7 displays sectional load change on bolts M9, M13 and M16. In the case of bolt M9, only Section 3 took load whereas loads on Sections 1 and 2 were decreasing, most likely due to rock relaxation near the rock face. A negative value in load change means the bolt has relaxed compared with its 'initial' tensioned state when the bolt condition was first measured. Negative or no load on Section 1 coincides with the observation that the rock face on the back was rather fractured. On bolts M13 and M16, it was Sections 2 and 3 that took most load changes with similar load distribution patterns. The load on Section 1 was decreasing for bolt M13 and the load on Section 1 for bolt M16 was increasing but rather small compared with the other two sections. As a consequence of the production blast presented earlier, sharp changes of sectional loads were also observed in the May 13 measurements. It is to note that even if bolts M9, M13 and M16 were adjacent one to another, load distributions on these bolts varied from bolt to bolt. These results suggest that ground conditions at the monitored area were quite sporadic from location to location. 
M9

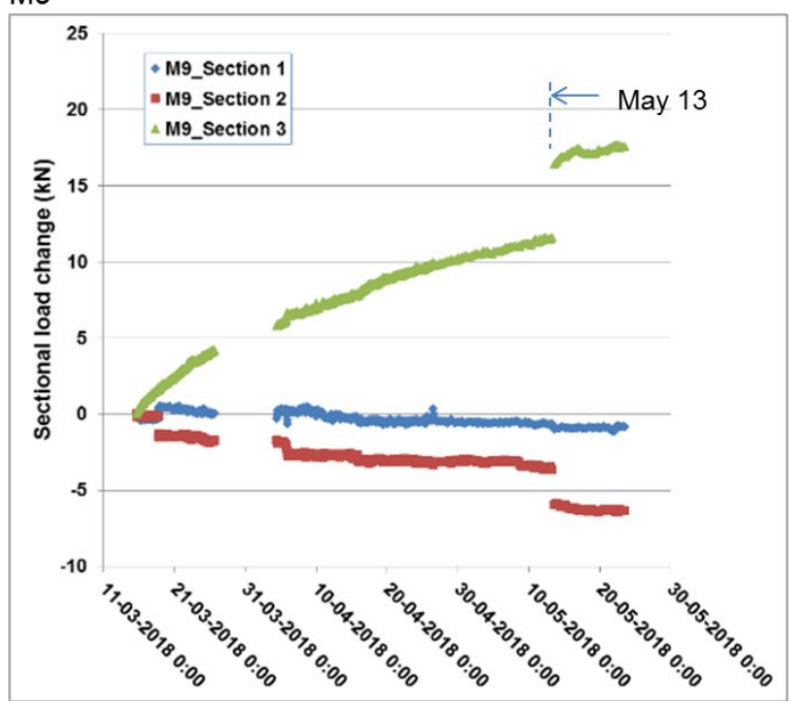

M13

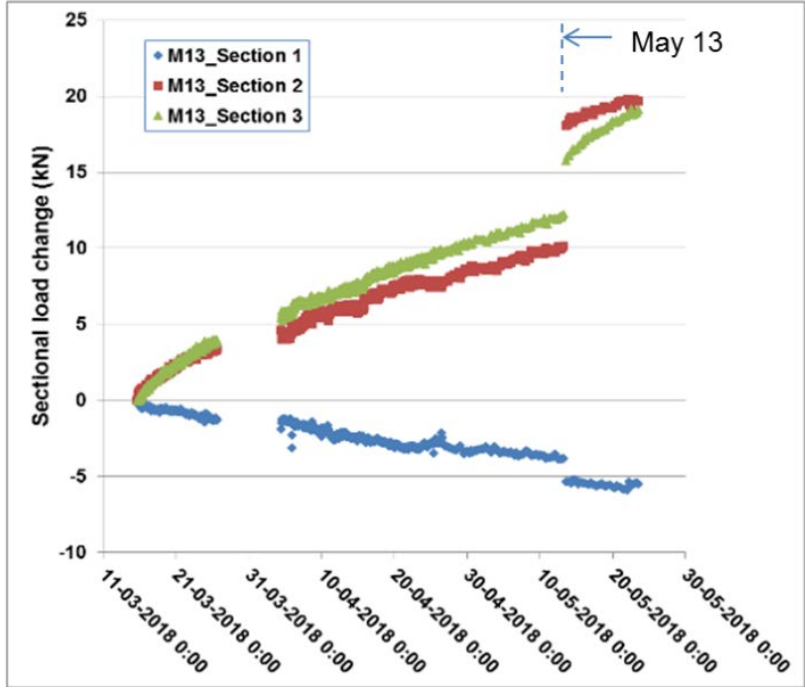

M16

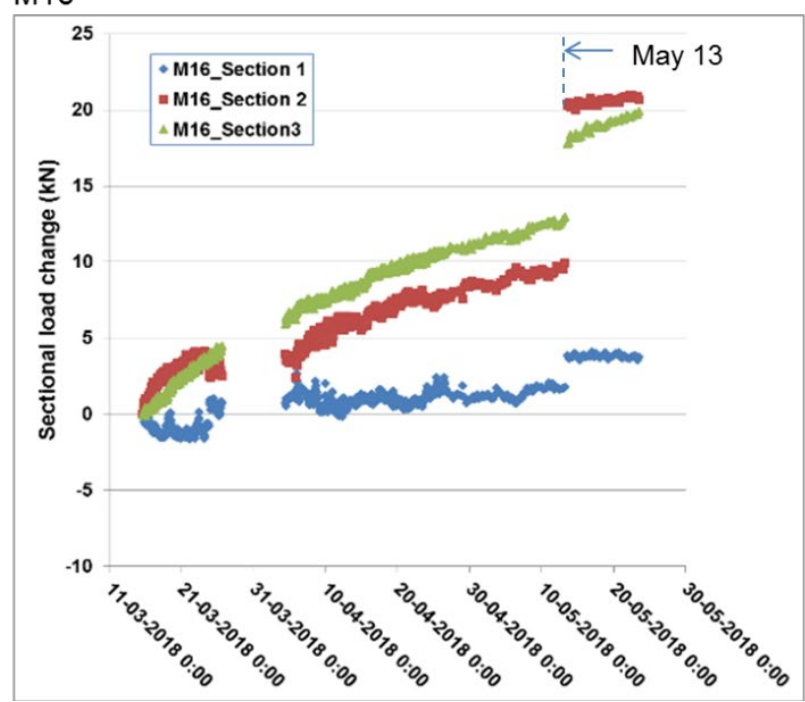

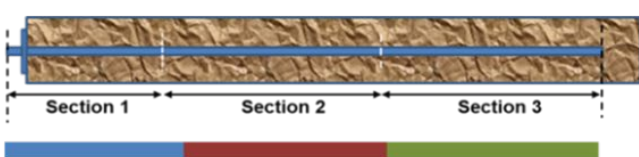
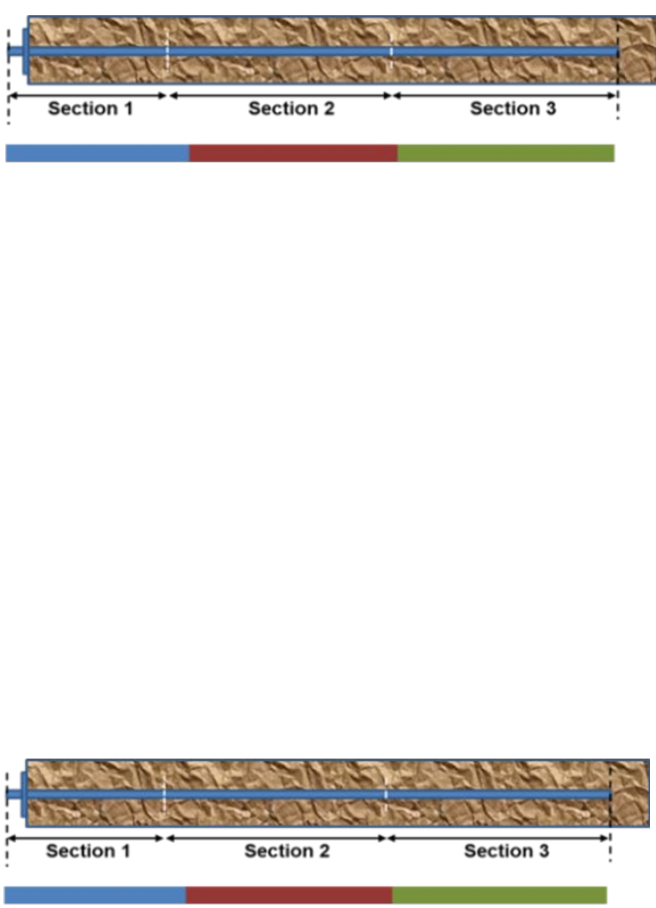

Figure 7 Sectional load change on bolts M9 (upper), M13 (middle) and M16 (bottom) at site A 
Figure 8 displays average load change over full length of instrumented rockbolts at site $B$. The results are obtained by using ultrasonic echo signals from the end of rockbolts. Bolt readings were taken on a weekly basis and using a portable RBS system. During the deployment period we noticed that some RBS signals were so weak that they could be totally immersed in the noise. When a signal was too weak to be reliably used, we would omit it, resulting in missing measurement points in the figure. Following the blast of April 15, 2018, the load measured on April 18, 2018 showed a sharp increase on all bolts. A parallel study showed that stress changes experienced by the instrumented rockbolts were in good agreement with measured local seismic activities. However, following the production blast of May 13, 2018, the instrumented bolts in this area did not detect any noticeable ground condition change. This was also in good agreement with a lack of seismic activities in this instrumented area following the blast. Again, the results show a tendency of increasing load from one sidewall of the tunnel to the other side, similar to the results at site $A$. However, the behaviour observed at site A was the opposite of the one reflected by the RBS sensors at site B. Opposite tendencies at these two sites of load variation from one sidewall of the tunnel to the other side would be revealed only through monitoring of clusters of rockbolts in small areas.

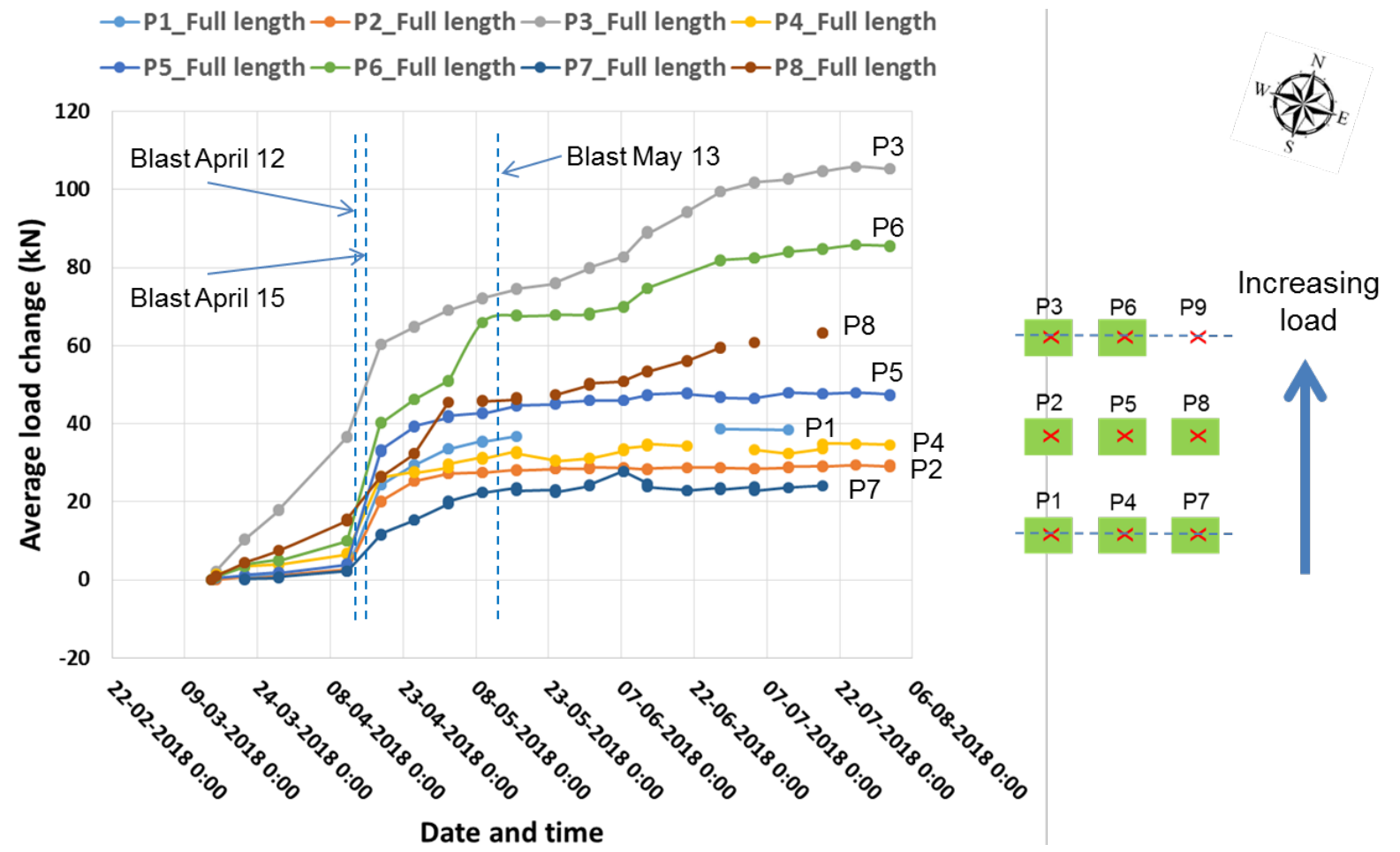

Figure 8 Average load change over full length of rockbolt at site B

The RBS technology is able to detect whether the load on a bolt has passed the yield strength of the bolt and plastic elongation associated with the yield. Figure 9 shows measured sectional load change and plastic deformation on Section 3 of bolt P3 at site B. In theory, the measured plastic elongation should be zero before the bolt has yielded. Due to the effect of varying temperature on propagation speeds of ultrasonic waves and noises in signals, there was an estimated uncertainty level of about $0.04 \%$ in plastic elongation measurement. If the measured plastic elongation is larger than $0.04 \%$, the bolt section is considered to have experienced confirmed yield. It is to note that $0.04 \%$ is rather small compared with the $9 \%$ nominal minimum elongation limit of the bolt. According to the results presented in Figure 9, Section 3 of bolt P3 already entered confirmed plastic deformation regime on June 20,2018. The onset of a plateau in the sectional load data suggests that bolt actually yielded around June 12, i.e. about eight days earlier. It is to point out the RBS technology measures the average load over a section. For a well-grouted bolt under stress, the load distribution over the bolt is expected to be non-uniform and a highly stressed area can yield far before the average load over the section reaches the nominal value of yield strength provided by the manufacturer. This explains why Section 3 of bolt P3 has yielded at an average sectional load of $95 \mathrm{kN}$, which is much lower than the $155 \mathrm{kN}$ nominal yield strength of a bare bolt. 

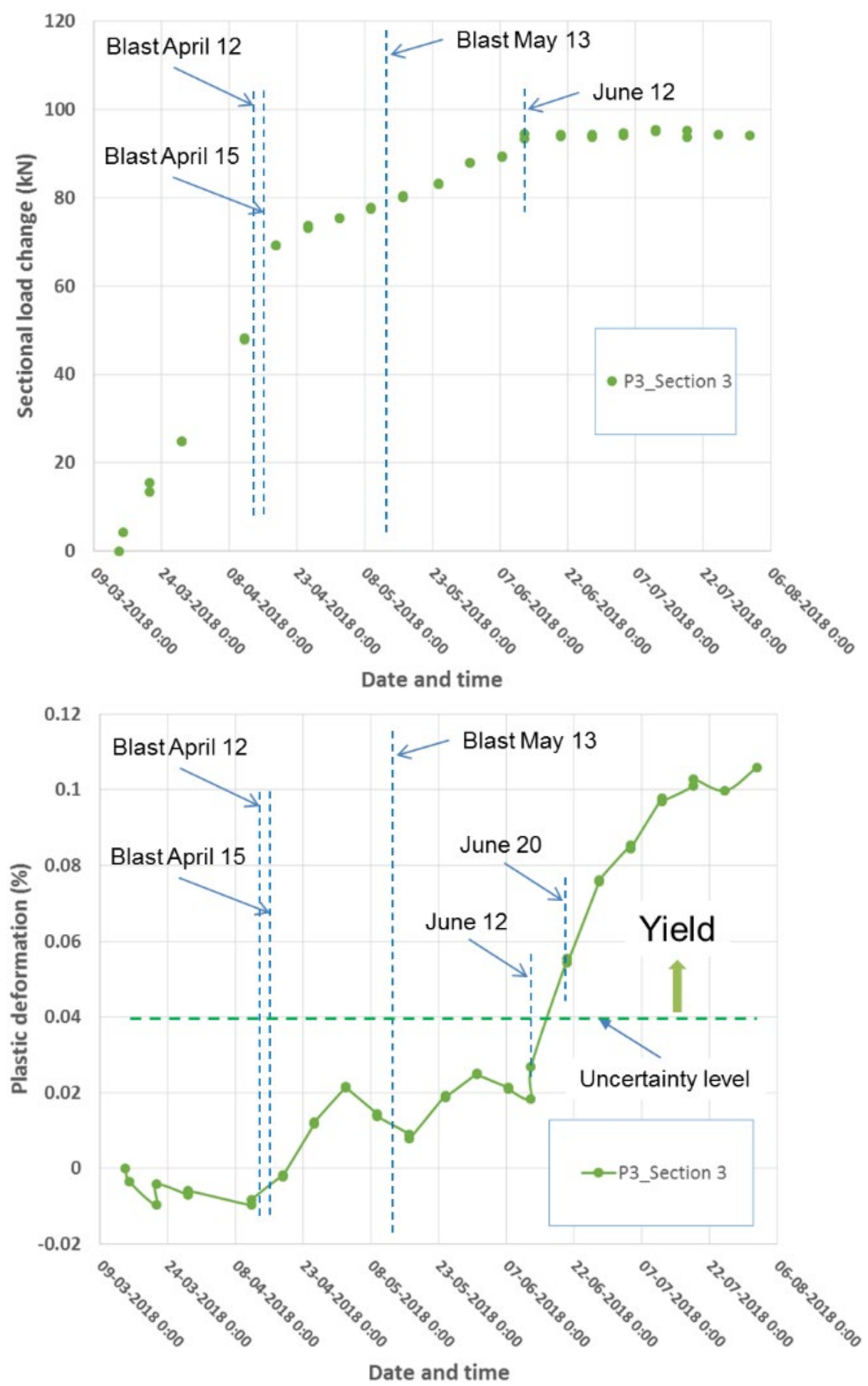

Figure 9 Average load change (upper) and plastic elongation (lower) on Section 3 of bolt P3 at site B

\section{Conclusion}

Ultrasonic RBS technology has proven to be capable of measuring load change and plastic elongation experienced by a rebar bolt or a section of a rebar bolt. The technology is compatible with existing bolters for installation of instrumented rockbolts. Not only does technology serve as a powerful tool for inspection or health monitoring of individual rockbolts, but also, when deployed on a large-scale and used on clusters of rockbolts, the RBS technology transforms instrumented rockbolts into a pervasive network of ground condition sensors. Field deployment results have demonstrated that clusters of instrumented bolts can 
provide much more insightful and reliable information about overall ground conditions and Therefore, monitoring clusters of instrumented rockbolts is recommended as being an effective practice for ground support monitoring. For commercialisation of the technology, robustness of sensors will need to be improved; and robust and energy efficient electronics will need to be developed.

\section{Acknowledgement}

The authors would like to express their deep gratitude to David Rocheleau, Antoine Hamel, Francis Boismenu, André Hamel, Christian Padioleau, Gaétan Veilleux and Caroline Hoang at National Research Council Canada, as well as Daniel Côté at Natural Resources Canada, for technical support. Sincere thanks to RBS Consortium Project members Agnico Eagle, Alamos Gold, Barrick Gold, Eldorado Gold, Goldcorp, IAMGOLD and Kirkland Lake Gold for their contributions and tremendous efforts in field testing the RBS Technology.

\section{Copyright notice}

(C) 2019 National Research Council of Canada

\section{References}

Beard, MD, Lowe, MJS \& Cawley, P 2002, 'Development of a guided wave inspection technique for rock bolts', Insight: Non-Destructive Testing and Condition Monitoring, vol. 44, no. 1, pp. 19-24.

Beard, MD, Lowe, MJS \& Cawley, P 2003, 'Ultrasonic guided waves for inspection of grouted tendons and bolts', Journal of Materials in Civil Engineering, vol. 15, pp. 212-218.

Charette, F \& Hyett, AJ 2013, 'Monitoring of dynamic energy resistant rockbolts: laboratory and field results', Proceedings of the 23rd World Mining Congress, Canadian Institute of Mining, Metallurgy and Petroleum, Montreal, Paper \#815.

Fishman, KL 2004, Condition Assessment and Evaluation of Rock Reinforcement Along Barron Mountain Rockcut, I-93, Woodstock, Phase I final report, viewed 2 July 2019, https://www.nh.gov/dot/org/projectdevelopment/materials/research/ projects/documents/13733I_report1.pdf

Fishman, KL 2005, Condition Assessment and Evaluation of Rock Reinforcement Along Barron Mountain Rockcut, l-93, Woodstock, Phase II final report, viewed 2 July 2019, https://www.nh.gov/dot/org/projectdevelopment/materials/research/ projects/documents/13733I_report2.pdf

Hyett, A 2013, Strain Measuring and Monitoring Device, US, Patent No. 2013054156 (A1).

Li, Z, Wang, Q, Li, S, Wang, D, Li, W \& Wang, H 2012, Fiber Bragg Grating Pre-stressed Force-measuring Rock Bolt, China, Patent No. CN202693170U.

Vlachopoulos, N, Cruz, D \& Forbes, B 2018, 'Utilizing a novel fiber optic technology to capture the axial responses of fully grouted rock bolts', Journal of Rock Mechanics and Geotechnical Engineering, vol. 10, pp. 222-235.

$\mathrm{Wu}, \mathrm{B}$, Sun, Y, He, C, Wang, X, Liu, Z \& Zhang, Q 2007, 'Application of high frequency ultrasonic guided waves to inspection of full-length-bonding bolt', Chinese Journal of Rock Mechanics and Engineering, vol. 26, no. 2, pp. 397-403.

$\mathrm{Yu}, \mathrm{JD}, \mathrm{Bae}, \mathrm{MH}$, Lee, IM \& Lee, JS 2013, 'Nongrouted ratio evaluation of rock bolts by reflection of guided ultrasonic waves', Journal of Geotechnical and Geoenvironmental Engineering, vol. 139, pp. 298-307.

Zou, DS, Cheng, J \& Yue, R 2010, 'Grout quality and its impact on guided ultrasonic waves in grouted rock bolts', Journal of Applied Geophysics, vol. 72, pp. 102-106. 
